\title{
Burden of pneumococcal pneumonia requiring ICU admission in France: 1-year prognosis, resources use, and costs
}

Claire Dupuis ${ }^{1,2,3 \dagger}$, Ayman Sabra ${ }^{4 \dagger}$, Juliette Patrier ${ }^{1}$, Gwendoline Chaize $^{5}$, Amine Saighi ${ }^{4}$, Céline Féger ${ }^{6}$, Alexandre Vainchtock ${ }^{5}$, Jacques Gaillat ${ }^{7}$ and Jean-François Timsit ${ }^{1,3^{*}}$

\begin{abstract}
Background: Community-acquired pneumonia (CAP), especially pneumococcal CAP (P-CAP), is associated with a heavy burden of illness as evidenced by high rates of intensive care unit (ICU) admission, mortality, and costs. Although well-defined acutely, determinants influencing long-term burden are less known. This study assessed determinants of 28-day and 1-year mortality and costs among P-CAP patients admitted in ICUs.

Methods: Data regarding all hospital and ICU stays in France in 2014 were extracted from the French healthcare administrative database. All patients admitted in the ICU with a pneumonia diagnosis were included, except those hospitalized for pneumonia within the previous 3 months. The pneumococcal etiology and comorbidities were captured. All hospital stays were included in the cost analysis. Comorbidities and other factors effect on the 28-day and 1 -year mortality were assessed using a Cox regression model. Factors associated with increased costs were identified using log-linear regression models.
\end{abstract}

Results: Among 182,858 patients hospitalized for CAP in France for 1 year, 10,587 (5.8\%) had a P-CAP, among whom 1665 (15.7\%) required ICU admission. The in-hospital mortality reached $22.8 \%$ at day 28 and $32.3 \%$ at 1 year. The mortality risk increased with age $>54$ years, malignancies (hazard ratio (HR) 1.54, 95\% Cl [1.23-1.94], $p=0.0002$ ), liver diseases (HR 2.08, 95\% Cl [1.61-2.69], $p<0.0001$ ), and the illness severity at ICU admission. Compared with nonICU-admitted patients, ICU survivors remained at higher risk of 1-year mortality. Within the following year, 38.2\% $(516 / 1350)$ of the 28 -day survivors required at least another hospital stay, mostly for respiratory diseases. The mean cost of the initial stay was $€ 19,008$ for all patients and $€ 11,637$ for subsequent hospital stays within 1 year. Oneyear costs were influenced by age (lower in patients $>75$ years old, $p=0.008)$, chronic cardiac $(+11 \%[0.02-0.19]$, $p=0.019)$, and respiratory diseases $(+11 \%[0.03-0.18], p=0.006)$.

Conclusions: P-CAP in ICU-admitted patients was associated with a heavy burden of mortality and costs at one year. Older age was associated with both early and 1-year increased mortality. Malignant and chronic liver diseases were associated with increased mortality, whereas chronic cardiac failure and chronic respiratory disease with increased costs.

\footnotetext{
*Correspondence: jean-francois.timsit@aphp.fr

${ }^{\dagger}$ Claire Dupuis and Ayman Sabra have contributed equally to this work

${ }^{1}$ AP-HP, Medical and Infectious Diseases Intensive Care Unit (MI2), Bichat-

Claude Bernard University Hospital, 46 rue Henri Huchard, 75018 Paris,

France

Full list of author information is available at the end of the article
} permits use, sharing, adaptation, distribution and reproduction in any medium or format, as long as you give appropriate credit to the original author(s) and the source, provide a link to the Creative Commons licence, and indicate if changes were made. The images or other third party material in this article are included in the article's Creative Commons licence, unless indicated otherwise in a credit line to the material. If material is not included in the article's Creative Commons licence and your intended use is not permitted by statutory regulation or exceeds the permitted use, you will need to obtain permission directly from the copyright holder. To view a copy of this licence, visit http://creativecommons.org/licenses/by/4.0/. The Creative Commons Public Domain Dedication waiver (http://creativeco mmons.org/publicdomain/zero/1.0/) applies to the data made available in this article, unless otherwise stated in a credit line to the data. 
Trial registration: N/A (study on existing database)

Keywords: Community-acquired pneumonia, Pneumococcal pneumonia, Streptococcus pneumoniae, Intensive care unit, Long-term outcome, Direct costs, Comorbidities

\section{Background}

Community-acquired pneumonia (CAP) causes a heavy burden of illness with high morbidity, mortality, and health-related costs [1-5]. In European countries with reliable coding systems, respiratory diseases are responsible for $15 \%$ of in-hospital deaths, with pneumonia being the second most important cause, and for $7 \%$ of hospital admissions, with pneumonia being the leading cause (2\%). A recent review across Europe reported a still high incidence of CAP, of $68-7000$ per 100,000 populations [4].

Among hospitalized CAP, the proportion of those requiring intensive care unit (ICU) admission ranges from 5 to $40 \%$ [6]; it was $22.7 \%$ in a recent US study [7]. Some scoring systems have been specifically set up to assist clinicians to identify patients who will require ICU admission $[8,9]$. However, these scores are focused to identify patients with short-term mortality. The factors associated with an increased risk of long-term mortality, and the magnitude of the associated increase are poorly known.

In addition, the burden of in-hospital management of CAP, due to pneumococci (P-CAP) and other etiologies, as well as management of associated comorbidities, generates high costs. Although the short-term mortality and in-hospital costs of P-CAP in France have already been estimated [10], little is known about the associated 1-year survival, burden of hospital care, and costs. However, the evaluation of the overall burden associated with CAP, and more specifically P-CAP, is instrumental to guide public health strategies for CAP prevention, such as targeting pneumococcal or influenza vaccination to highrisk groups. This is of notable importance in France as a French study conducted in 2007-2012 showed only $2 \%$ of the patients admitted in the ICU for severe P-CAP were vaccinated against pneumococcal infections [11].

The objectives of this study were to ascertain the overall burden associated with ICU-admitted P-CAP in France in terms of in-hospital mortality and the associated direct costs, during both the initial hospital stay and within the year following the P-CAP onset.

\section{Methods}

\section{Study objectives}

The study objective aimed to evaluate the burden of severe P-CAP in France related to the initial hospital stay and subsequent hospital stays within the year following the pneumonia onset, regarding in-hospital mortality, and hospital-related costs. The study is based on an exhaustive administrative registry that collects data of all hospital stays in France.

\section{Database}

Study data were obtained from the Programme de Médicalisation des Systèmes d'Information (PMSI) database, the health administrative database which records all discharges from public and private hospitals in France. This registry allows the chaining of all hospital stays of individual patients.

\section{Study population}

All patients admitted to ICUs with a diagnosis of P-CAP were included. The International Statistical Classification of Diseases, 10th Revision (ICD-10), used for CAP diagnosis and comorbidities are detailed in the Online Data Supplement. A CAP-related hospitalization was any hospitalization with a principal diagnosis of pneumonia or a secondary diagnosis of pneumonia if the principal diagnosis was respiratory failure or sepsis. For P-CAP, the diagnoses were based on ICD-10 code J13: "Pneumonia due to Streptococcus pneumoniae" or B953 "Streptococcus pneumoniae as the cause of diseases classified elsewhere" and pneumonia. Patients with a hospital stay with a diagnosis of $\mathrm{P}$-CAP within the previous 3 months were excluded. The severity of acute illness at ICU admission was reported through the Simplified Acute Physiology Score II (SAPS II), mandatory for all ICU stays. Additional file 1 provides additional details, including details on the variables related to the initial hospital stay and the subsequent stays within the following year (see Additional file 1: e-Tables 1 \& 2).

\section{Costs evaluation}

All hospital stays, encompassing those related to the initial ICU admission as well as subsequent hospitalizations within the following year (detailed in the supplement), were included in the cost analysis, with the details of inclusion stay costs (including the supplement related to ICU) and 1-year follow-up costs. Healthcare consumption items taken into account are described in Additional file 1.

Costings were restricted to direct in-hospital costs and determined from the perspective of the French 
Table 1 Characteristics of patients with pneumococcal community-acquired pneumonia admitted in intensive care unit

\begin{tabular}{|c|c|c|c|}
\hline Characteristics of the patients & All $(n=1665)$ & 28-day survivors $(n=1286)$ & $\begin{array}{l}\text { One-year } \\
\text { survivors } \\
(n=1127)\end{array}$ \\
\hline Male gender & $1108(67 \%)$ & $834(65 \%)$ & $730(64.8 \%)$ \\
\hline Age (median [Q1;Q3], years) & $65[55 ; 76]$ & $64[53 ; 75]$ & $64[53 ; 74]$ \\
\hline $0-54$ years old ${ }^{a}$ & $394(23.7 \%)$ & $345(26.8 \%)$ & $322(28.6 \%)$ \\
\hline $55-64$ years old & $409(24.6 \%)$ & $327(25.4 \%)$ & $290(25.7 \%)$ \\
\hline $65-75$ years old & $424(25.5 \%)$ & $316(24.6 \%)$ & $277(24.6 \%)$ \\
\hline$\geq 76$ years old & $438(26.3 \%)$ & $298(23.2 \%)$ & $238(21.1 \%)$ \\
\hline Alcohol & $429(25.8 \%)$ & $332(25.8 \%)$ & $289(25.6 \%)$ \\
\hline Tobacco & $590(35.4 \%)$ & $476(37.0 \%)$ & $415(36.8 \%)$ \\
\hline No comorbidities & $86(5.1 \%)$ & $82(6.4 \%)$ & $79(7.0 \%)$ \\
\hline At least one & $1579(94.8 \%)$ & $1204(93.6 \%)$ & $1048(93.0 \%)$ \\
\hline Asplenia/hyposplenia & $12(0.7 \%)$ & $9(0.7 \%)$ & $6(0.5 \%)$ \\
\hline Cancers / hemopathy & $497(29.8 \%)$ & $347(27.0 \%)$ & $278(24.7 \%)$ \\
\hline Auto-immune disorders & $146(8.8 \%)$ & $111(8.6 \%)$ & $97(8.6 \%)$ \\
\hline Organ transplant recipient ${ }^{b}$ & $267(16.0 \%)$ & $194(15.1 \%)$ & $157(13.9 \%)$ \\
\hline HIV & $32(1.9 \%)$ & $21(1.6 \%)$ & $19(1.7 \%)$ \\
\hline Diabetes mellitus & $415(24.9 \%)$ & $321(25.0 \%)$ & $275(24.4 \%)$ \\
\hline Chronic cardiac failure & $518(31.1 \%)$ & $379(29.5 \%)$ & $297(26.4 \%)$ \\
\hline Chronic respiratory diseases $^{c}$ & $861(51.2 \%)$ & $688(53.5 \%)$ & $594(52.7 \%)$ \\
\hline Renal diseases $^{d}$ & $239(14.4 \%)$ & $172(13.4 \%)$ & $140(12.4 \%)$ \\
\hline Chronic renal insufficiency & $202(12.1 \%)$ & $146(11.4 \%)$ & $118(10.5 \%)$ \\
\hline Liver diseases $^{e}$ & $272(16.3 \%)$ & $170(13.2 \%)$ & $142(12.6 \%)$ \\
\hline Cirrhosis & $165(9.9 \%)$ & $106(8.2 \%)$ & $88(7.8 \%)$ \\
\hline Liver failure & $118(7.1 \%)$ & $61(4.7 \%)$ & $49(4.3 \%)$ \\
\hline SAPSII & $48( \pm 19)$ & $45( \pm 17)$ & $44( \pm 17)$ \\
\hline Mechanical ventilation & $1103(66.2 \%)$ & $789(61.4 \%)$ & $706(62.6 \%)$ \\
\hline Noninvasive ventilation & $987(59.3 \%)$ & $818(63.6 \%)$ & $708(62.8 \%)$ \\
\hline Vasopressor use & $1032(62.0 \%)$ & $728(56.6 \%)$ & $640(56.8 \%)$ \\
\hline Renal replacement therapy & $227(13.6 \%)$ & $105(8.2 \%)$ & $94(8.3 \%)$ \\
\hline Length of initial stay in hospital (days) & $23( \pm 22)$ & $24( \pm 21)$ & $24( \pm 21)$ \\
\hline Length of stay in ICU (days) & $13( \pm 16)$ & $12( \pm 15)$ & $12( \pm 15)$ \\
\hline \multicolumn{4}{|c|}{ ICU: intensive care unit; HIV: human immunodeficiency virus; SAPS: Simplified Acute Physiological Score. Quantitative data: mean ( \pm SD); qualitative data: number (\%) } \\
\hline \multicolumn{3}{|c|}{ a Only two patients were less than $18:$ aged 9 and 17} & b Organ transplant comprised solid organ transplant and hematopoietic stem cells transplant \\
\hline \multicolumn{4}{|c|}{ ` Chronic respiratory diseases included COPD, asthma, and respiratory insufficiency } \\
\hline \multicolumn{4}{|c|}{$\begin{array}{l}{ }^{\mathrm{d}} \text { Chronic renal diseases included nephrotic syndrome, renal tubular and interstitial nephritis, renal tubular and interstitial lesions related to drugs or heavy metals, } \\
\text { renal tubular and interstitial lesions related to other diseases, other renal tubular and interstitial lesions, chronic kidney disease, and renal failure }\end{array}$} \\
\hline
\end{tabular}

social security system, according to the methodological rules of the French Technical Agency for Information on Hospitalization. Valuation of hospital stays included the 2014-2015 tariffs of the GHS (using upper and lower limits), with supplements and additional expenses related to drugs and medical devices. For private hospitals, clinicians' fees were added. Costs were expressed in 2016 Euros.

\section{Statistical methodology}

All hospital stays were considered to be independent and included into the analyses. Standard descriptive statistics were performed for the whole cohort. Data were summarized as frequencies and percentages for categorical variables and medians with interquartile ranges or means with standard deviations for continuous variables.

Log-linear regression models were constructed to explore predictive factors associated with costs in 
Table 2 Independent risk factors for an early versus late death of ICU-admitted patients with pneumococcal communityacquired pneumonia (note: other comorbidities did not independently impact the survival) (multivariate analysis, Cox model)

\begin{tabular}{|c|c|c|c|c|c|c|c|c|c|c|c|c|}
\hline \multirow[t]{2}{*}{$\begin{array}{l}\text { Independent risk factors } \\
\text { (multivariate model) }\end{array}$} & \multicolumn{4}{|c|}{$\begin{array}{l}\text { Overall in-hospital mortality } \\
N=1665\end{array}$} & \multicolumn{4}{|c|}{$\begin{array}{l}\text { 28-day in-hospital mortality } \\
N=1665\end{array}$} & \multicolumn{4}{|c|}{$\begin{array}{l}\text { One-year in-hospital mortality } \\
N=1350\end{array}$} \\
\hline & HR & $95 \% \mathrm{C}$ & & $p$ Value & HR & $95 \% \mathrm{C}$ & & $p$ Value & HR & $95 \% \mathrm{Cl}$ & & $p$ Value \\
\hline $0-54$ & 1.00 & - & - & & 1.00 & - & - & & 1.00 & - & - & \\
\hline $55-64$ & 1.61 & $1.20-$ & 2.16 & 0.0015 & 1.40 & $0.96-$ & 2.05 & 0.0807 & 1.92 & $1.20-$ & 3.06 & 0.0067 \\
\hline $65-75$ & 1.94 & $1.46-$ & 2.57 & $<0.0001$ & 1.61 & $1.12-$ & 2.32 & 0.0103 & 2.46 & $1.56-$ & 3.87 & 0.0001 \\
\hline $76+$ & 3.28 & 2.49- & 4.32 & $<0.0001$ & 2.93 & $2.06-$ & 4.16 & $<0.0001$ & 3.74 & $2.40-$ & 5.84 & $<0.0001$ \\
\hline Female gender & 1.08 & $0.90-$ & 1.31 & 0.3998 & 1.01 & 0.79 & 1.29 & 0.9586 & 1.21 & $0.91-$ & 1.63 & 0.1945 \\
\hline Cancer / malignant hemopathy & 1.60 & 1.34 & 1.91 & $<0.0001$ & 1.54 & $1.23-$ & 1.94 & 0.0002 & 1.66 & $1.27-$ & 2.18 & 0.0002 \\
\hline Chronic liver diseases & 1.99 & 1.62 & 2.44 & $<0.0001$ & 2.53 & 1.96- & 3.26 & $<0.0001$ & 1.80 & $1.28-$ & 2.53 & 0.0008 \\
\hline
\end{tabular}

adults. Factors significantly associated with the outcomes assessed in the univariate analysis $(p$ value $<0.1)$ were included in the multivariate analysis with backward selection.

Cox regression was used to assess the effect of comorbidities on adult death. This method provides an estimate of the hazard ratio. The mortality was evaluated separately for early mortality ( $\leq 28$ days after ICU admission, initial stay or the following) and late mortality (within the first year excluding the first 28 days) to respect proportional hazard hypotheses. Proportionality assumption of Cox models was checked graphically, and Schoenfeld residuals were calculated if clinically relevant.

The $p$ values $<0.05$ were considered significant. Data were analyzed using $\mathrm{R}$ (versions 3.2.3 and 3.6.1; R Core Team, Vienna, Austria).

\section{Results}

\section{Study population}

Of a total of 182,858 patients hospitalized for CAP in France during the year 2014 and without any hospitalization for pneumonia within the previous 3 months, 10,587 (5.8\%) patients had P-CAP, from which a small minority of patients required ICU admission (1665 patients, $0.9 \%$ of all patients with CAP; $15.7 \%$ of all patients with P-CAP) (Fig. 1). On the basis of the French population in 2014, the incidence of ICU-admitted patients with P-CAP was 2.53 per 100,000 populations and 5.97 per 100,000 populations over 50 years of age.

Table 1 depicts the main characteristics of ICU-admitted patients with P-CAP. Patients were mostly men (1108/1,665, 67\%), of median age 65 years [Q1-Q3 interquartile range (IQR), 55-76]. Only two patients were below 18 years of age. Almost all $(1579,94.8 \%)$ had at least one comorbidity; most frequently chronic respiratory diseases $(n=861,51.7 \%)$, chronic cardiac failure $(n=518$,

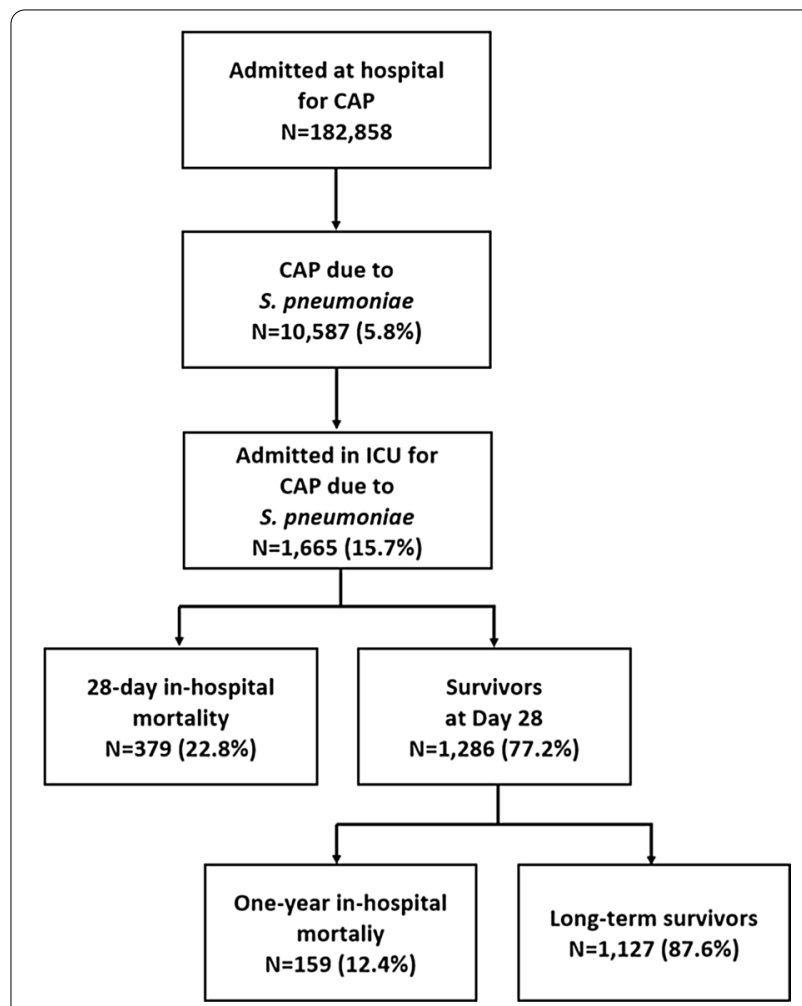

Fig. 1 Patient flowchart. CAP: community-acquired pneumonia; S. pneumoniae: Streptococcus pneumoniae; ICU: intensive care unit

31.1\%), malignant disease (both solid tumors and hematological malignancies) $(497,29.8 \%)$ and diabetes (415, 24.9\%). Alcohol and/or tobacco abuse was reported in 740 (44.4\%) patients. At ICU admission, the mean (SD) SAPS II was 48 [19], 62\% of patients required vasopressor agents, and $93.1 \%$ required ventilation support: mechanical ventilation for $66.2 \%(1103 / 1665)$ of patients for a median of 7 [IQR, 3-14] days and noninvasive ventilation 
for $59.3 \%(987 / 1665)$ of patients for a median of 3 [IQR, 1-6] days in median. Their median [IQR] ICU and hospital length of stay (LOS) were 8 [4-16] and 17 [10-29] days, respectively. Among survivors of the initial stay, the median ICU and hospital LOS was 8 [4-15] and 18 [1130] days, respectively. The median LOS in the ICU was similar across age-groups at 7 [4-16] days below 55 years old, 9 [5-18] days for those aged 55-64 years, 9 [5-16] days for those aged 65-75 years, and 7 [4-14] days for those older than 75 years.

\section{Outcomes}

Patients with an early death (379 patients, $22.8 \%$ ) were more often men (72\% vs. $65 \%$ in survivors) and older (median age 71 [60-80] vs. 64 [53-75] years).

Overall, $516(31.0 \%)$ patients were readmitted at hospital within the following year, most of them once (300, 18.0\%). However, 25 (1.5\%) were readmitted 4 times, and 25 (1.5\%) patients were admitted 5 times or more. Most of the readmissions were due to diseases of the respiratory system $(73.7 \%$, lower respiratory tract diseases for one-third of them) and circulatory system (13.6\%). The mean (SD) cumulated duration of the stays during the following year was 10.7 (14.3) days. Although the mean number of stays was rather similar regardless of their age-group, the cumulative duration increased with age, from 9.0 (10.9) days for the 55-to-64 age-group to 11.3 (13.7) days for the 65-to-75 age-group (further data in Additional file 1: e-Table 1).

Within the following year, the in-hospital mortality rate among ICU-admitted patients was 32.3\% (538/1665), compared with $13.4 \%(1196 / 8922)$ of those hospitalized not admitted in ICU, and their in-hospital mortality occurred earlier, at a median [IQR] of 0.7 [0-2] months versus $1.7[0-5]$ months for the other inpatients. Among ICU-admitted P-CAP patients, 70.4\% of deaths occurred within the first 28 days and 9.5\% during the second and third months (e-Fig. 1). The Kaplan-Meier estimate of the 1-year in-hospital survival was $67.7 \%$ (95\% CI 65.5\%$70.0 \%$ ) for ICU-admitted patients versus $86.2 \%$ (95\% CI $85.2 \%-87.2 \%)$ for non-ICU-admitted patients (log-rank test $p<0.0001$ ) (Fig. 2). The increase in the risk of death of ICU-admitted patients persisted up to 1 year for survivors to the first stay (see Additional file 1: e-Fig. 1).

The illness severity at ICU admission increased the 28-day but not 1-year mortality. In contrast, the factors that independently impacted both short- and long-term mortality were age above 54 years, malignant diseases (HR 1.54, 95\% CI [1.23-1.94], $p=0.0002$, and HR 1.66, 95\% CI [1.27-2.18], $p=0.0002$, respectively) and chronic liver diseases (HR 2.08, 95\% CI [1.61-2.69], $p<0.0001$, and HR 1.80, 95\% CI [1.28-2.53], $p<0.01$, respectively) (Table 2).

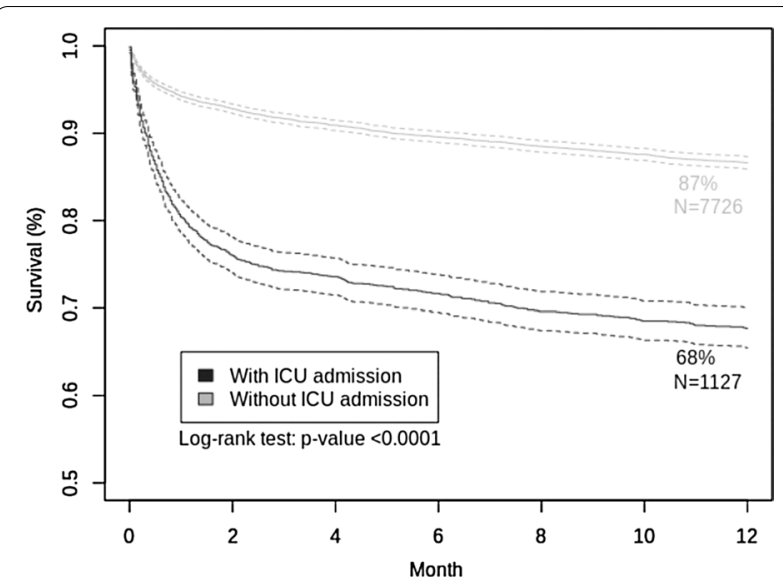

Fig. 2 One-year survival curve of patients with pneumococcal community-acquired pneumonia admitted in the intensive care unit (ICU; $n=1665)$ versus those who did not require admission in the ICU $(n=8922)$. Kaplan-Meier estimates of the 1-year mortality: $0.6769(95 \% \mathrm{Cl} 0.6997 ; 0.6548)$ for patients admitted in the ICU, versus 0.8619 (95\% Cl 0.8724; 0.8515) for those not requiring ICU admission (log-rank test $p$ value $<0.0001$ )

\section{Direct costs associated with the initial and subsequent hospital stays}

For all ICU-admitted patients, the mean (SD) cost of the initial hospital stays was $€ 19,008(€ 17,218)$ (Additional file 1, e-Table 2). The mean (SD) cost of the initial stay was similar among those who survived or died at one-year $(€ 18,613(€ 16,013)$ vs. $€ 19,834(€ 19,491)$; Additional file 1, e-Table 2). The mean (SD) cost of the subsequent hospital stays following the initial ICU admission for P-CAP was $€ 11,637(€ 16,500)$ for the subset of patients who were subsequently re-hospitalized.

Compared with that of patients aged $18-54$ years, the cost of the initial stay was $11 \%$ higher for those aged 55-64 years, whereas it was $11 \%$ lower for the patients aged $\geq 76$ years. The cost of the subsequent hospital stays was also lower in both higher age-groups compared with that of patients aged $18-54$ years: by $28 \%$ for patients aged $55-64$ years and $14 \%$ for those aged $\geq 76$. The mean cost per month of life gained increased with age (Additional file 1, e-Table 2).

The 1-year hospital stays among survivors showed that a moderate illness severity at ICU admission was independently associated with increased costs $(+22 \%$ (beta index $0.20,95 \%$ CI [0.11-0.29]), whereas costs were significantly decreased for the most severely ill patients $(-19 \%(-0.21,95 \%$ CI $[-0.22:-0.10]$, $p=0.0003$ ) (Table 3). Chronic cardiac failure and chronic respiratory diseases were independent risk factors for increased costs. 


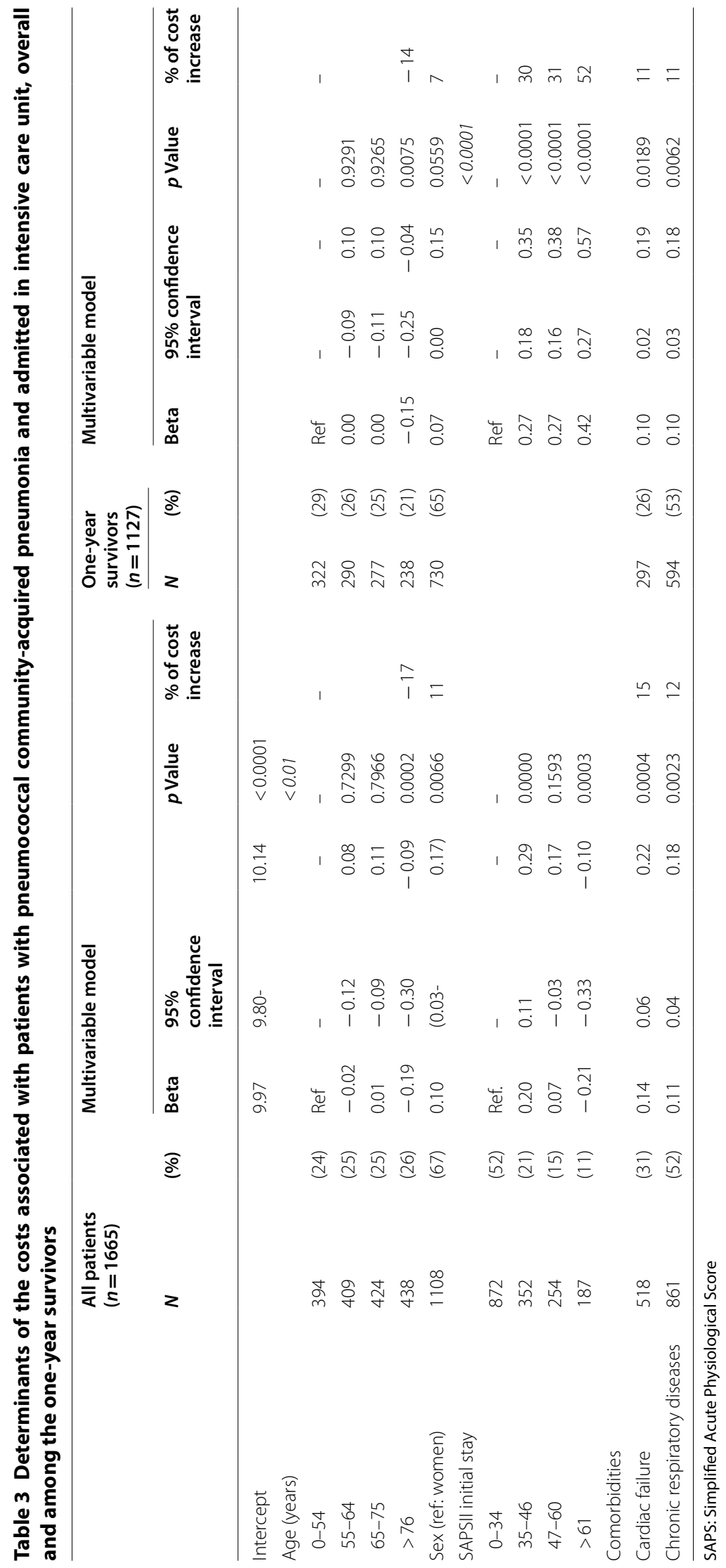




\section{Discussion}

This study describes a comprehensive survey of all patients with pneumococcal pneumonia hospitalized in the ICU in France for 1 year and the associated burden in terms of in-hospital mortality and direct costs. Although many studies on patients with pneumococcal pneumonia are focused on the risk factors for ICU admission and the 28-day mortality rates, this study broadened the scope to the risk factors for increased mortality and costs during both the initial and all the subsequent hospital stays within the year following the ICU admission. We showed that the early mortality was correlated with the initial illness severity at ICU admission, age, and two comorbidities, malignant diseases and chronic liver diseases, whereas the initial illness severity was no longer a risk factor for 1-year mortality. The in-hospital costs were decreased in patients with early mortality, i.e., the most severely ill at admission. Unlike mortality, the comorbidities that impacted in-hospital costs were chronic cardiac and respiratory diseases.

The 28-day mortality rate of our study is consistent with that reported by others. In a multicenter French study on 614 ICU-admitted patients with severe P-CAP, the mortality rate was $18.9 \%$ [11]. Age, gender, and organ failures at ICU admission were more strongly associated with hospital mortality than comorbidities as expressed through the Charlson index [11]. This population was slightly less severely ill, as their median SAPS II at ICU admission was at 43 [IQR 32-57], whereas our patients had a median SAPS II at 48, and more than $60 \%$ were mechanically ventilated and required vasopressor agents. The mortality rate of $29 \%$ observed in another French study on invasive pneumococcal infections, mainly P-CAP, comprised $48 \%$ severely ill patients, of which $31 \%$ were admitted in ICUs [12]. Another French study on ICU patients with invasive pneumococcal infection reported a similar 28-day mortality rate of $19.8 \%$ [13]. Diabetes mellitus was the only comorbidity independently associated with increased mortality (odds ratio $1.91,95 \%$ CI [1.23-3.03], $p=0.006)$, in that study that contrasts to our study where diabetes had no prognostic value in multivariate analysis. The frequent complication of diabetes with chronic cardiovascular diseases may explain why diabetes itself is not eventually associated with prognosis in our multivariate model.

After the initial ICU stay, the 1-year in-hospital mortality was $12 \%$ and increased with age and comorbidities including malignant and liver diseases. Our observed mortality is similar to the overall 1 -year post-ICU mortality reported by a Dutch study [14] but lower than that of a US study after ICU stay for sepsis [15] and a Finnish study in ICU patients with severe CAP [16]. The prognostic value for the long-term mortality of any type of preexisting comorbidities was also reported by others [17-22]. More specifically, our study showed that the 1-year mortality is correlated with some comorbidities rather than with the illness severity at ICU admission, as already highlighted by others [23-26]. A French study on the 1-year survival of ICU survivors reported an OR at 1.65 [95\% CI 1.13-2.42] for patients with active malignant disease [24]. Another study reported a hazard ratio of 1.98 [95\% CI 1.17-3.37] for the long-term mortality in hospitalized patients with CAP with cancer [25]. Similarly, the independent impact of chronic liver diseases on the mortality of ICU patients was already described [23, 26]. However, the impact of these severe complications on the 1-year mortality might be more related to their own severity than to the CAP episode that triggered the initial hospital admission. Of note, cardiac events, frequently reported as jeopardizing the medium- and longterm outcomes of hospitalized CAP patients [17, 21, 27], were not a major cause of readmissions.

In our study, the mean cost of the initial ICU stay was slightly above $€ 19,000$. In a previous study conducted in France in 2011-2014 which evaluated the direct costs associated with P-CAP, the cost for the subset of the ICU-admitted patients was $€ 14,385$, that is, lower than observed in our study [10]. With regard to age, the costs in our study ranged approximately $€ 18-20,000$ for the initial stay and were slightly lower for patients older than 75 years, which may be explained by the higher early mortality in this age-group. Interestingly, the costs of the subsequent stays for the younger adults (1854 years) were twice as high as those for the oldest adults (> 75 years). Importantly, on its own, the high age was not an independent risk factor for increased costs in our study. Because of the differences in health systems, costs differ from one country to another, and direct comparisons must be made with caution.

The 1-year hospital costs were closely linked to rehospitalizations and were experienced by one patient out of three in our study. This rate is lower than the $40 \%$ readmission rate within 3 months observed in the USA for sepsis [16], and the overall $72 \%$ readmission rate observed for hospitalized CAP patients [28]. It may reflect the French policy for ICU admission of patients that selects patients who will benefit the most from their ICU stay with a better intermediate-term prognosis. Importantly, chronic cardiac and respiratory diseases were associated with a substantial increase in 1-year costs, and readmissions were by far mostly due to these two comorbidities. Of note, the proportion of readmission due to chronic respiratory diseases was higher than the proportion of this comorbidity in our population, suggesting that the ICU admission for P-CAP may be associated with a worsening of the underlying respiratory diseases. The 
respective impact of $\mathrm{P}-\mathrm{CAP}$ and chronic illness by itself on the readmissions was not addressed by our study.

In our study, specific comorbidities but not age were independent prognosis factors for the pneumococcal disease burden, that supports French recommendations, which are solely comorbidities driven for adult patients [29]. This is in contrast to other guidelines for which age directs vaccination recommendations [30, 31]. The four comorbidities that we identified as drivers for an increased CAP burden are included in most immunization recommendations. However, malignant diseases, which are all included in the recent French recommendations [32], are often limited elsewhere to some subpopulations, such as metastatic stage, or some specific hematological malignancies. Patients with cancer, although at higher risk of increased 1-year in-hospital mortality, as observed in our study and others [33], exhibit a low rate of pneumococcal vaccination [34,35]. A recent French study showed a 10\% rate among patients with comorbidities at risk [12]. A single-institution study focusing on 99 patients with gastrointestinal cancer yielded a pneumococcal vaccination rate of $10.1 \%$ (95\% CI [4.1-16]) [36]. As shown in several studies, childhood vaccination programs contribute to herd immunity, thus partly protecting non-vaccinated adults [37, 38]. However, this protection of adults has been deemed insufficient in France, despite a high coverage of vaccination among children [39]. Vaccination among adults including those older than 65 years has been shown to be efficient [40]. Healthcare professionals, cancer societies, and other societies advocate for increasing this vaccination rate, which some vaccination programs increased successfully [36]. Cardiovascular diseases are the leading cause of mortality of diabetic patients [41], which may explain the lack of a signal due to diabetes mellitus in our model. Beyond specific comorbidities, the immunization coverage reported for elderly residents from French long-term nursing facilities was low at 27\% (95\% CI [21-34]) among those with targeted comorbidities and 17\% (95\% CI [1420]) overall [42].

Despite its strengths, this study has some limitations. It relies on an administrative database that mainly has budgetary purposes. Therefore, the coding of some diseases such as the P-CAP diagnosis might be suboptimal. The reliability is not that of a clinical database monitored against source data. However, we used ICD10 of the coding system, which showed more reliability for the pneumonia diagnosis, and we combined codes for an improved accuracy [43, 44]. In addition, some types of data were not available, such as the intensity of signs and symptoms at admission; the use of some resources, such as the dialysis procedures; or the immunization status of the patients. However, as discussed earlier, the rate of vaccinated people is low in France, even among at-risk patients. It is another limitation that we did not have the tests used and their results and microbiological data related to the susceptibility profile of the serotype of the pneumococcal strains, as well as the adequacy of antimicrobial therapy.

Another limitation is that this database collects solely in-hospital data. Therefore, we do not have any insight regarding what happened outside of the hospital, such as the out-of-hospital mortality rate. However, a French study showed that the rate of in-hospital deaths in 2008 ranged approximately $60 \%$ of deaths for the patients aged between 40 and 89 years and that these rates were stable over 15 years [45]. Therefore, we can evaluate our rate of missing death-related data at approximately $40 \%$ of our known decedents. In addition, solely data on acute hospital stays were collected, and we did not collect whether the patient was discharged home or to a rehabilitation facility. Another limitation is the lack of indirect cost data, e.g., those related to ambulatory consultations, drugs, and medical procedures. Finally, while potentially several control groups would have been of interest, such as patients admitted in the ICU with CAP not due to S. pneumoniae, or pneumococcal invasive infections other than CAP, or other reasons besides CAP patients for being transferred into the ICU.

\section{Conclusions}

Although severe pneumococcal pneumonia in France was associated with a survival of $81 \%$ at discharge, the Kaplan-Meier estimates of the 1-year survival were $68 \%$. The 1-year prognosis was mainly influenced by age and comorbidities, such as chronic liver diseases and malignant diseases. The burden of severe pneumococcal pneumonia is not only a heavy mortality but also a high rate of new hospital stays within the year following the pneumonia onset. Overall, the in-hospital costs within the year following pneumonia were higher than $€ 22,000$ and significantly increased in patients with cardiac diseases and chronic respiratory diseases. Overall, severe pneumococcal pneumonia in patients with chronic comorbidities, such as malignant diseases, chronic liver, and cardiac and respiratory diseases, is associated with a heavy 1-year burden, and it might be prevented by a better compliance to the current guidelines for pneumococcal vaccination.

\section{Supplementary information}

The online version contains supplementary material available athttps://doi. org/10.1186/s13054-020-03442-z. 


\begin{abstract}
Additional file 1. Further details on Methods, on data regarding the hospital stays (e-Table 1 and e-Table 2), and on the 1-year survival curves of patients (e-Fig. 1). In Methods, further details are provided on the codes used for the identification of the pneumonia diagnosis, of the comorbidities and procedures used, and of the pneumonia etiology. e-Table 1. Characteristics of the new hospital stays within the year following the CAP-related hospitalization, overall and according to the age group, among those with at least one new hospital stay. e-Table 2. Direct costs of the initial hospital stay and of the subsequent hospital stays within the first year, by patient with pneumococcal communityacquired pneumonia and admitted in intensive care unit, overall, according to the one-year outcome, and by age group. e-Fig. 1. Comparative survival curves of patients with pneumococcal pneumonia (P-CAP) admitted in intensive care unit (ICU), (A) from the hospitalization to 3 months after (3-month survivors: $74.2 \%(1,235 / 1,665)$ ICU-admitted patients vs. $91.7 \%(8,179 / 8,922)$ non ICU-admitted patients); (B), among the 3-months survivors, from 3 to 12 months after the hospitalization $(91.3 \%(1,127 / 1,235)$ ICU-admitted patients vs. $94.5 \%(7,726 / 8,179)$ non-ICU-admitted patients).
\end{abstract}

\section{Acknowledgements}

The authors thank Kevin Laupland for his critical review.

\section{Authors' contributions}

$C D, J P, C F, A y S, A m S, J G$, and JFT contributed to the study design and the interpretation of the results. GC and AV provided input on the study design, conducted the data analysis, and contributed to the interpretation of results. All authors contributed to the manuscript and read and approved the final manuscript.

\section{Funding}

This study was funded by Pfizer France.

\section{Availability of data and materials}

The datasets used and/or analyzed during the current study are available from Pfizer's authors on reasonable request.

\section{Ethics approval and consent to participate}

Not applicable, study on existing administrative database.

\section{Consent for publication}

Not applicable.

\section{Competing interests}

$\mathrm{CD}$ and JP have no competing interests. AyS and AmS are employees of Pfizer France. CF is CEO of EMIBiotech, contracted by Pfizer to contribute to coordinate the study results discussion and the draft of the manuscript. GC and AV are employees of HEVA, contracted by Pfizer France to conduct the statistical analysis. JG is a member of advisory boards and gave lectures for Pfizer, Sanofi, and MSD. JFT received fees for advisory boards of Astellas, Bayer, Beckton-Dickinson, Gilead, Medimune, Merck, Nabriva, Paratek, and Pfizer. The research group of JFT received grants from $3 \mathrm{M}$, Merck, Pfizer; JFT is the principal investigator of one RCT of CAP sponsored by the French ministry of health (MULTICAP; PHRCN-16-0595; ClinicalTrials.gov Identifier: NCT03452826).

\section{Author details}

${ }^{1}$ AP-HP, Medical and Infectious Diseases Intensive Care Unit (MI2), BichatClaude Bernard University Hospital, 46 rue Henri Huchard, 75018 Paris, France.

${ }^{2}$ Université de Paris, INSERM IAME, U1137, Team DesCID, 75018 Paris, France.

${ }^{3}$ Medical ICU, Gabriel-Montpied University Hospital, Clermont-Ferrand, France.

${ }^{4}$ Pfizer France, Paris, France. ${ }^{5}$ HEVA, Lyon, France. ${ }^{6}$ EMIBiotech, Paris, France.

${ }^{7}$ Infectious Diseases Department, Annecy-Genevois Hospital, Annecy, France.

Received: 12 September 2020 Accepted: 16 December 2020

Published online: 10 January 2021

\section{References}

1. Hayes BH, Haberling DL, Kennedy JL, Varma JK, Fry AM, Vora NM. Burden of pneumonia-associated hospitalizations: United States, 2001-2014. Chest. 2018;153(2):427-37.

2. McLaughlin JM, Khan FL, Thoburn EA, Isturiz RE, Swerdlow DL. Rates of hospitalization for community-acquired pneumonia among US adults: a systematic review. Vaccine. 2019.

3. Peyrani P, Mandell L, Torres A, Tillotson GS. The burden of communityacquired bacterial pneumonia in the era of antibiotic resistance. Expert Rev Respir Med. 2019;13(2):139-52.

4. Torres A, Cilloniz C, Blasi F, Chalmers JD, Gaillat J, Dartois N, et al. Burden of pneumococcal community-acquired pneumonia in adults across Europe: a literature review. Respir Med. 2018;137:6-13.

5. Welte T, Torres A, Nathwani D. Clinical and economic burden of community-acquired pneumonia among adults in Europe. Thorax. 2012;67(1):71-9.

6. Garnacho-Montero J, Barrero-Garcia I, Gomez-Prieto MG, MartinLoeches I. Severe community-acquired pneumonia: current management and future therapeutic alternatives. Exp Rev Anti-Infect Therapy. 2018;16(9):667-77.

7. Divino V, Schranz J, Early M, Shah H, Jiang M, DeKoven M. The annual economic burden among patients hospitalized for community-acquired pneumonia (CAP): a retrospective US cohort study. Curr Med Res Opin. 2019:1.

8. Mandell LA, Wunderink RG, Anzueto A, Bartlett JG, Campbell GD, Dean $\mathrm{NC}$, et al. Infectious diseases society of america/american thoracic society consensus guidelines on the management of community-acquired pneumonia in adults. Clin Infect Dis. 2007;44(Suppl 2):S27-72.

9. Charles PG, Wolfe R, Whitby M, Fine MJ, Fuller AJ, Stirling R, et al. SMART-COP: a tool for predicting the need for intensive respiratory or vasopressor support in community-acquired pneumonia. Clin Infect Dis. 2008;47(3):375-84.

10. Saba G, Andrade LF, Gaillat J, Bonnin P, Chidiac C, Illes HG, et al. Costs associated with community acquired pneumonia in France. Eur J Health Econ. 2018;19(4):533-44.

11. Bedos JP, Varon E, Porcher R, Asfar P, Le Tulzo Y, Megarbane B, et al. Host-pathogen interactions and prognosis of critically ill immunocompetent patients with pneumococcal pneumonia: the nationwide prospective observational STREPTOGENE study. Intensive Care Med. 2018:44(12):2162-73.

12. Danis K, Varon E, Lepoutre A, Janssen C, Forestier E, Epaulard O, et al. Factors associated with severe nonmeningitis invasive pneumococcal disease in Adults in France. Open Forum Infect Dis. 2019;6(12):510.

13. Garrouste-Orgeas M, Azoulay E, Ruckly S, Schwebel C, de Montmollin E, Bedos JP, et al. Diabetes was the only comorbid condition associated with mortality of invasive pneumococcal infection in ICU patients: a multicenter observational study from the Outcomerea research group. Infection. 2018;46(5):669-77.

14. Brinkman S, de Jonge E, Abu-Hanna A, Arbous MS, de Lange DW, de Keizer NF. Mortality after hospital discharge in ICU patients. Crit Care Med. 2013:41(5):1229-36.

15. Prescott HC, Angus DC. Enhancing recovery from sepsis: a review. JAMA. 2018;319(1):62-75.

16. Karhu J, Ala-Kokko TI, Ylipalosaari P, Ohtonen P, Laurila JJ, Syrjala H. Hospital and long-term outcomes of ICU-treated severe community- and hospital-acquired, and ventilator-associated pneumonia patients. Acta Anaesthesiol Scand. 2011;55(10):1254-60.

17. Cangemi R, Calvieri C, Falcone M, Bucci T, Bertazzoni G, Scarpellini MG, et al. Relation of cardiac complications in the early phase of communityacquired pneumonia to long-term mortality and cardiovascular events. Am J Cardiol. 2015;116(4):647-51.

18. Corrales-Medina VF, Suh KN, Rose G, Chirinos JA, Doucette S, Cameron DW, et al. Cardiac complications in patients with community-acquired pneumonia: a systematic review and meta-analysis of observational studies. PLoS Med. 2011;8(6):e1001048.

19. Mortensen EM, Kapoor WN, Chang CC, Fine MJ. Assessment of mortality after long-term follow-up of patients with community-acquired pneumonia. Clin Infect Dis. 2003;37(12):1617-24

20. Restrepo MI, Faverio P, Anzueto A. Long-term prognosis in communityacquired pneumonia. Curr Opin Infect Dis. 2013;26(2):151-8. 
21. Waterer GW, Kessler LA, Wunderink RG. Medium-term survival after hospitalization with community-acquired pneumonia. Am J Respir Crit Care Med. 2004;169(8):910-4.

22. Wesemann T, Nullmann H, Pflug MA, Heppner HJ, Pientka L, Thiem U. Pneumonia severity, comorbidity and 1-year mortality in predominantly older adults with community-acquired pneumonia: a cohort study. BMC Infect Dis. 2015;15:2

23. Das V, Boelle PY, Galbois A, Guidet B, Maury E, Carbonell N, et al. Cirrhotic patients in the medical intensive care unit: early prognosis and long-term survival. Crit Care Med. 2010;38(11):2108-16.

24. Gayat E, Cariou A, Deye N, Vieillard-Baron A, Jaber S, Damoisel C, et al. Determinants of long-term outcome in ICU survivors: results from the FROG-ICU study. Crit Care. 2018;22(1):8.

25. Holter JC, Ueland T, Jenum PA, Muller F, Brunborg C, Froland SS, et al. Risk factors for long-term mortality after hospitalization for communityacquired pneumonia: a 5-Year prospective follow-up study. PLoS ONE. 2016;11(2):e0148741.

26. Zahar JR, Timsit JF, Garrouste-Orgeas M, Francais A, Vesin A, DescorpsDeclere A, et al. Outcomes in severe sepsis and patients with septic shock: pathogen species and infection sites are not associated with mortality. Crit Care Med. 2011;39(8):1886-95.

27. Rae N, Finch S, Chalmers JD. Cardiovascular disease as a complication of community-acquired pneumonia. Curr Opin Pulm Med. 2016;22(3):212-8.

28. Johnstone J, Eurich DT, Majumdar SR, Jin Y, Marrie TJ. Long-term morbidity and mortality after hospitalization with community-acquired pneumonia: a population-based cohort study. Medicine. 2008;87(6):329-34.

29. HCSP FHCOPH. Recommendations with regards to the vaccinations for the prevention of pneumococcal infections in adults. 2017.

30. Bonnave C, Mertens D, Peetermans W, Cobbaert K, Ghesquiere B, Deschodt M, et al. Adult vaccination for pneumococcal disease: a comparison of the national guidelines in Europe. Eur J Clin Microbiol Infect Dis. 2019;38(4):785-91.

31. Matanock A, Lee G, Gierke R, Kobayashi M, Leidner A, Pilishvili T. Use of 13-valent pneumococcal conjugate vaccine and 23-valent pneumococ cal polysaccharide vaccine among adults aged $\geq 65$ years: updated recommendations of the Advisory Committee on Immunization Practices. MMWR Morb Mortal Wkly Rep. 2019;68(46):1069-75.

32. Ministry FH. [Calendar and recommendation for vaccinations - update 2019]. 2019. https://solidarites-sante.gouv.fr/IMG/pdf/calendrier_vacci nal_maj_17avril2019.pdf. Last accessed 8 Dec 2020

33. Backhaus E, Berg S, Andersson R, Ockborn G, Malmstrom P, Dahl M, et al. Epidemiology of invasive pneumococcal infections: manifestations, incidence and case fatality rate correlated to age, gender and risk factors. BMC Infect Dis. 2016;16:367.

34. Yee SS, Dutta PR, Solin LJ, Vapiwala N, Kao GD. Lack of compliance with national vaccination guidelines in oncology patients receiving radiation therapy. J Support Oncol. 2010;8(1):28-34.

35. Zarco-Marquez S, Volkow-Fernandez P, Velazquez-Acosta C, EchanizAviles G, Carnalla-Barajas MN, Soto-Nogueron A, et al. Invasive and complicated pneumococcal infection in patients with cancer. Rev Invest Clin. 2016;68(5):221-8.

36. Sitte J, Frentiu E, Baumann C, Rousseau H, May T, Bronowicki JP, et al. Vaccination for influenza and pneumococcus in patients with gastrointestinal cancer or inflammatory bowel disease: A prospective cohort study of methods for improving coverage. Aliment Pharmacol Ther. 2019;49(1):84-90.

37. Shiri T, Khan K, Keaney K, Mukherjee G, McCarthy ND, Petrou S. Pneumococcal disease: A systematic review of health utilities, resource use, costs, and economic evaluations of interventions. Value Health. 2019;22(11):1329-44.

38. Simonsen L, Taylor RJ, Young-Xu Y, Haber M, May L, Klugman KP. Impact of pneumococcal conjugate vaccination of infants on pneumonia and influenza hospitalization and mortality in all age groups in the United States. mBio. 2011;2(1):309

39. Health FP. [Invasive pneumococcal infections - French epidemiological data] 2020 [updated 20-jan-2020. Available from: https://www.santepubli quefrance.fr/maladies-et-traumatismes/maladies-a-prevention-vaccinale/ infections-a-pneumocoque/donnees/.

40. Bonten MJ, Huijts SM, Bolkenbaas M, Coauthors C. Vaccine against pneumococcal pneumonia in adults. N Engl J Med. 2015;373(1):93.

41. Strain WD, Paldánius PM. Diabetes, cardiovascular disease and the microcirculation. Cardiovasc Diabetol. 2018;17(1):57.

42. Guthman J-P, France SP. French survey on the immunization coverage, January 2011. Immunization coverage against seasonal influenza in target groups and measurement of vaccine efficacy. Immunization coverage with diphtheria-tetanus-polio (DTP) and pneumococcal vaccines in persons 65 years of age and older 2011. https://www.santepubliquefr ance.fr/maladies-et-traumatismes/maladies-a-prevention-vaccinale/dipht erie/documents/rapport-synthese/enquete-nationale-de-couverture -vaccinale-france-janvier-2011.-couverture-vaccinale-contre-la-gripp e-saisonniere-dans-les-groupes-cibles-et-mesur.

43. Smithee RB, Markus TM, Soda E, Grijalva CG, Xing W, Shang N, et al. Pneumonia hospitalization coding changes associated with transition from the 9 th to 10th revision of International Classification of Diseases. Health Serv Res Manag Epidemiol. 2020;7:2333392820939801.

44. Yoon J, Chow A. Comparing chronic condition rates using ICD-9 and ICD10 in VA patients FY2014-2016. BMC Health Serv Res. 2017;17(1):572.

45. Gisquet E, Aouba A, Aubry R, Jougla E, Rey G. Where does one die in France? Analysis of death certificates 1993-2008. Bull Epidemiol Hebdo. 2012;48:547-51.

\section{Publisher's Note}

Springer Nature remains neutral with regard to jurisdictional claims in published maps and institutional affiliations.
Ready to submit your research? Choose BMC and benefit from:

- fast, convenient online submission

- thorough peer review by experienced researchers in your field

- rapid publication on acceptance

- support for research data, including large and complex data types

- gold Open Access which fosters wider collaboration and increased citations

- maximum visibility for your research: over $100 \mathrm{M}$ website views per year

At BMC, research is always in progress.

Learn more biomedcentral.com/submissions 